\title{
Photochemical and thermal intramolecular 1,3-dipolar cycloaddition reactions of new 0 -stilbene- methylene-3-sydnones and their synthesis
}

\author{
Kristina Butković ${ }^{1,2}$, Željko Marinić ${ }^{3}$, Krešimir Molčanov ${ }^{4}$, \\ Biserka Kojić-Prodić ${ }^{4}$ and Marija Šindler-Kulyk ${ }^{* 1}$
}

\section{Full Research Paper}

\section{Address:}

${ }^{1}$ Department of Organic Chemistry, Faculty of Chemical Engineering and Technology, University of Zagreb, Marulićev trg 19, 10000

Zagreb, Croatia, ${ }^{2}$ present address: Galapagos istraživački centar, Prilaz baruna Filipovića 29, 10000 Zagreb, Croatia, ${ }^{3}$ Center for NMR, Rudjer Bošković Institute, Bijenička cesta 54, 10000 Zagreb, Croatia and ${ }^{4}$ Laboratory for Chemical and Biological Crystallography, Department of Physical Chemistry, Rudjer Bošković Institute, Bijenička cesta 54, 10000 Zagreb, Croatia

\section{Email:}

Marija Šindler-Kulyk ${ }^{\star}$ - marija.sindler@fkit.hr

${ }^{*}$ Corresponding author

Keywords:

[3 + 2] cycloaddition; isoindoles; nitrile imines; pyrazoles; sydnones

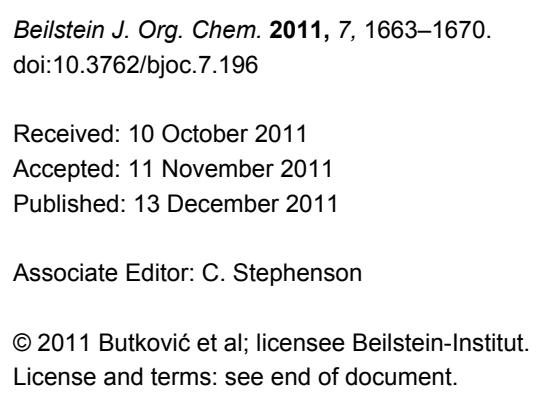

\begin{abstract}
New trans- and cis-o-stilbene-methylene-sydnones 3a,b were synthesized by transforming the trans- and cis-o-aminomethylstilbene derivative, obtained by reduction of corresponding $o$-cyano derivatives, into glycine ester derivatives (43 and $31 \%$ yield) followed by hydrolysis ( 90 and $96 \%$ yield), nitrosation and ring closure with acetic acid anhydride (30 and $40 \%$ yield). The products were submitted to photochemical and thermal intramolecular [3+2] cycloadditions to afford diverse heteropolycyclic compounds. Photochemical reactions afforded cis-3-(4-methylphenyl)-3a,8-dihydro-3H-pyrazolo[5,1-a]isoindole (11, 12.5\% yield) and trans-3-(4-methylphenyl)-3a,8-dihydro-3H-pyrazolo[5,1- $a$ ]isoindole (12, 5\% yield). Thermal reactions afforded 3-(4-methylphenyl)-3,3a,8,8a-tetrahydroindeno[2,1-c]pyrazole (14, 50\% yield) and 11-(4-methylphenyl)-9,10-diazatricyclo[7.2.1.0 $\left.0^{2,7}\right]$ dodeca2,4,6,10-tetraene $(\mathbf{1 5}, 22 \%$ yield).
\end{abstract}

\section{Introduction}

Sydnones belong to the group of five-membered heterocyclic compounds referred to as being "mesoionic" and have been widely studied since their discovery [1-5]. They can be represented as hybrids of a number of mesomeric ionic structures (Figure 1).
One of the most characteristic reactions of sydnones is the intermolecular 1,3-dipolar cycloaddition. In the presence of acetylenic or ethylenic dipolarophiles, sydnones undergo cycloaddition reactions, which can be induced thermally $[4,6,7]$ or photochemically [8-17], giving different pyrazole and/or pyra- 


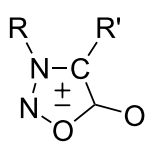
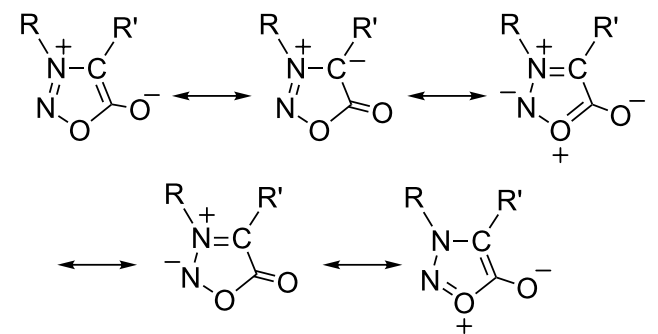

Figure 1: Resonance structures of the sydnone ring.

zoline derivatives, depending on the applied dipolarophile (Scheme 1). Namely, sydnones are masked 1,3-dipoles that by photolysis give nitrile imine intermediates, or in thermal reactions react as cyclic azomethine imines.<smiles>[R]C1=NN([R1])C([R])C1[R]</smiles><smiles>[R]c1nn([R])c([R])c1[R]</smiles><smiles>[R]C1=NN([R1])C([R])C1[R]</smiles>
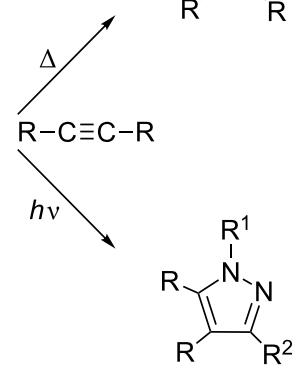

Scheme 1: Thermal and photochemical intermolecular [3 + 2] cycloadditions.

Intramolecular 1,3-dipolar cycloadditions of sydnone derivatives have not been as thoroughly investigated, and so far only a few examples are known [18-20]. Photochemically induced intramolecular 1,3-dipolar cycloadditions have been studied on 3,4-disubstituted sydnone derivatives [18,19] (Figure 2, A and B), wherein indolopyrazole and pyrazolobenzoxazine structures are formed (Figure 2, C and D).

Heimgartner and coworkers also carried out the thermally induced reaction of 3-(o-allylphenyl)-4-phenylsydnone (A) and obtained the cycloadduct E (Figure 2) with the oxycarbonyl group remaining in the structure [18].

We have been studying photochemical reactions of conjugated heterostilbene derivatives in which the sydnone moiety is part<smiles>C=CCc1ccccc1-n1cc(O)c(-c2ccccc2)n1</smiles>

A
B

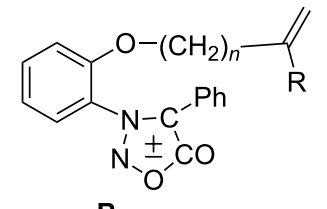<smiles>c1ccc(C2=NN3c4ccccc4CC3C2)cc1</smiles>

C<smiles>[R]C12COc3ccccc3N1N=C(c1ccccc1)C2</smiles>

D

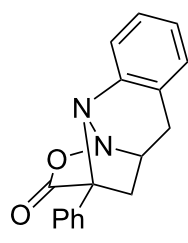

E
Figure 2: Illustration of intramolecular [3 + 2] cycloadditions.

of a heterostilbene [17] (1, Figure 3) or is directly attached at the ortho position to the stilbene 2 [21-23]. Upon photolysis of compound $\mathbf{1}$, where the sydnone moiety is part of a heterostilbene system, cis-trans isomerization was the main process, and no intramolecular cycloadducts were found owing to the unfavourable conformation of the formed intermediate in the trans configuration. The existence of the nitrile imine intermediate as a result of competitive photolysis of the sydnone moiety was confirmed on irradiation of $\mathbf{1}$ in the presence of acrolein and isolation of the pyrazoline derivative (F, Figure 3$)$ [17]. In the case of stilbenylsydnones $\mathbf{2}$, where the sydnone moiety is directly connected to the ortho position of the stilbene, the cyclization of the formed nitrile imine intermediate leading to benzodiazepine ring closure (G, Figure 3 ) was the<smiles></smiles>

1<smiles></smiles>

2<smiles>Cc1ccc(C=Cc2ccccc2C[n+]2ccon2)cc1</smiles><smiles>C=Cc1ccccc1/C=C/C1=NN([AlH2])C(CO)C1</smiles><smiles>[R]C1=NNc2ccccc2C=C1c1ccc([R])cc1</smiles>

G 
main intramolecular process [22]. In a continuation of our interest in the synthesis of heteropolycyclic compounds we extended our research to new stilbene-sydnone derivatives 3 (Figure 3). In such a system, where two chromophores, stilbene and sydnone, are divided by a methylene bridge, an intramolecular 1,3-dipolar cycloaddition and the formation of diverse polycyclic compounds could be expected. Herein we describe, for the first time, the synthesis of cis- and trans-3-(stilbenylmethyl)sydnones and their photochemical and thermal intramolecular transformations to heteropolycyclic structures.

\section{Results and Discussion}

In the investigation of 3-\{2-[2-(4-tolyl)ethenyl]phenyl\}methylsydnones, $\mathbf{3 a}$ (trans) and $\mathbf{3 b}$ (cis), were prepared by a sequence of reactions (Scheme 2) starting from $o$-cyanotoluene (see Supporting Information File 1 for full experimental data). Bromination of $o$-cyanotoluene afforded 2-(bromomethyl)benzonitrile (4) [24], which was transformed to triphenylphosphonium salt 5 [25] followed by Wittig reaction with 4-methylbenzaldehyde to 2-(4-methylstyryl)benzonitrile $(\mathbf{6 a}, \mathbf{b})$ [26]. The product was obtained as a mixture of $\mathbf{6 a}$ (trans isomer, $40 \%$ ) and $\mathbf{6 b}$ (cis isomer, $60 \%$ ).
The isomers were separated by column chromatography and further treated separately to achieve the final products in cis and trans configurations. Reduction of $\mathbf{6 a}$ (trans) or $\mathbf{6 b}$ (cis) with $\mathrm{LiAlH}_{4}$ in anhydrous ether afforded amino derivative 7a (trans, $94 \%)$ or $7 \mathbf{b}($ cis, $93 \%)$. In the ${ }^{1} \mathrm{H}$ NMR spectra new signals from the methylene protons appeared at $3.88 \mathrm{ppm}$ (7a) and $3.62 \mathrm{ppm}$ (7b) confirming the reduction. By further nucleophilic substitution, from $7 \mathbf{a}$ (trans) or $\mathbf{7 b}$ (cis) and ethyl bromoacetate, the ester $\mathbf{8 a}$ (trans) or $\mathbf{8 b}$ (cis) was prepared. On purification by column chromatography, the byproducts, obtained by disubstitution reaction of the amino compound, were separated, and the pure 8a (43\%) or $\mathbf{8 b}(31 \%)$ was isolated. The obtained esters showed the presence of the carbonyl group at $\sim 1740 \mathrm{~cm}^{-1}$ in the IR spectra and the carbonyl carbon at $\sim 172 \mathrm{ppm}$ in the ${ }^{13} \mathrm{C}$ NMR spectra. The esters 8a or $\mathbf{8 b}$ were hydrolysed to the amino acid $\mathbf{9 a}$ (trans, 90\%) or $\mathbf{9 b}$ (cis, 96\%). The obtained amino acids were transformed to $N$-nitroso glycine $\mathbf{1 0 a}$ or $\mathbf{1 0 b}$ and, without isolation or further purification, were submitted to dehydration with acetic acid anhydride to give sydnone 3a (trans) or $\mathbf{3 b}$ (cis). After column chromatography the pure $\mathbf{3 a}(30 \%)$ or $\mathbf{3 b}(42 \%)$ was isolated. The best indication that the sydnone structures were formed was

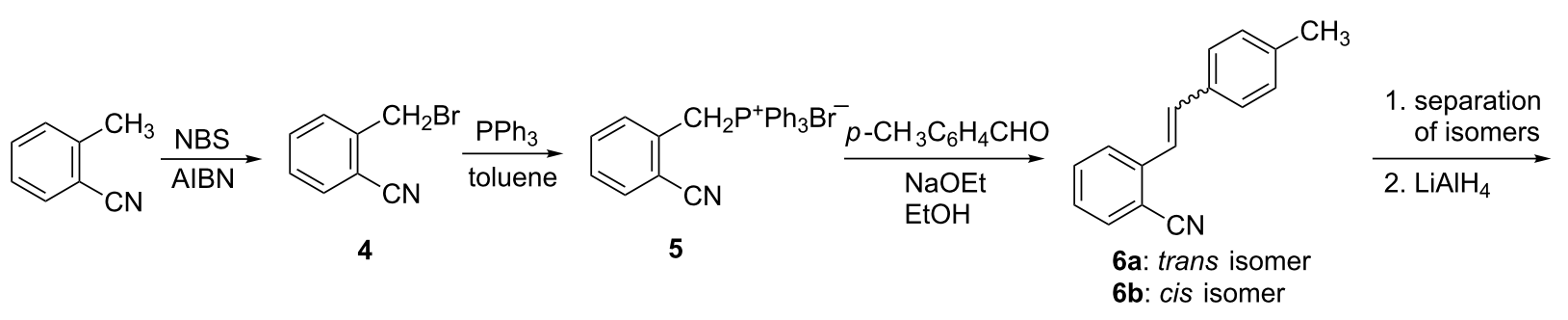<smiles>CCOC(=O)C(=O)OCC(=O)OCCN</smiles><smiles>CCOC(=O)CNCc1ccccc1C=Cc1ccc(C)cc1</smiles><smiles>Cc1ccc(C=Cc2ccccc2CNCC(=O)O)cc1</smiles>

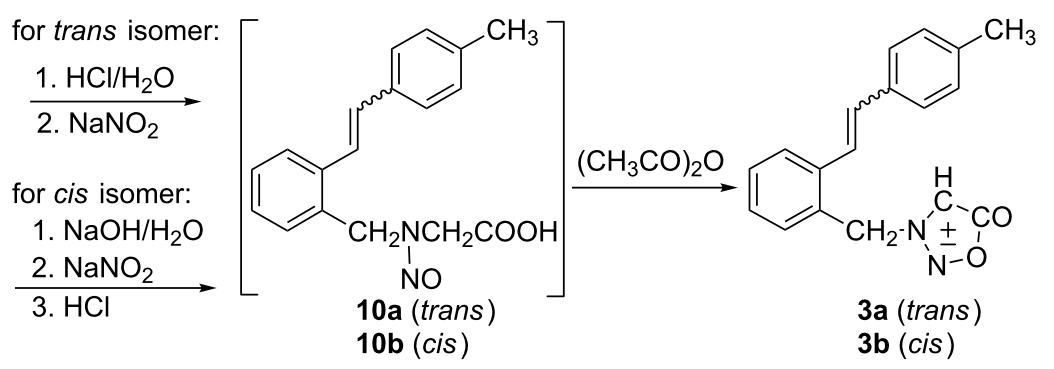


given by the singlet at $\sim 6 \mathrm{ppm}$ in the ${ }^{1} \mathrm{H}$ NMR spectrum, characteristic for the proton $\mathrm{H}-4$ in the sydnone ring, as well as those in the ${ }^{13} \mathrm{C}$ NMR spectrum, namely the $\mathrm{CH}$ and $\mathrm{CO}$ sydnone carbons at $\sim 94$ and $\sim 169 \mathrm{ppm}$, respectively.

The irradiation experiments with the trans isomer (3a) or cis isomer (3b) were performed in $\sim 10^{-3} \mathrm{M}$ benzene solution in a Rayonet reactor at $300 \mathrm{~nm}$ under anaerobic conditions (purged with argon). The absorption maximum of trans isomer (3a) is at $300 \mathrm{~nm}(\varepsilon$ 37453) and of cis isomer (3b) at $291 \mathrm{~nm}(\varepsilon$ 16228), thus upon irradiation both isomers were excited. The irradiation of the isomers was performed until full conversion. The irradiation of either the trans or cis isomer, or of the mixture of isomers, resulted in the formation of two products in the same mutual ratio, along with large amounts of unidentified highmolecular-weight products. Separation by column chromatography in combination with thin layer chromatography gave dihydropyrazolo-isoindoles, 11 (12.5\%) and 12 (5\%) (Scheme 3).

The structure of the photoproducts was determined by spectroscopic methods. The molecular ions of $\mathbf{1 1}$ and 12, $\mathrm{m} / \mathrm{z} 248$ in the mass spectra, indicate that the structures have lost $\mathrm{CO}_{2}$ relative to the starting compound. In the ${ }^{1} \mathrm{H}$ and ${ }^{13} \mathrm{C}$ NMR spectra, the signals are found in an area which is characteristic for saturated cyclic compounds. The major product is assigned to compound 11 based on the following data: In ${ }^{1} \mathrm{H}$ NMR spectrum the signals at $4.98 \mathrm{ppm}$ and $4.43 \mathrm{ppm}$ are doublets with coupling constants of $15.6 \mathrm{~Hz}$ and are assigned to geminal protons G-1 and G-2. The other two signals at 4.92 and $4.24 \mathrm{ppm}$ are also doublets but with coupling constants of $10.8 \mathrm{~Hz}$. Based on the interaction of the proton at 5.88 with the proton at $4.92 \mathrm{ppm}$ in the NOESY spectrum, the doublet at 5.88 is assigned to proton $\mathrm{H}-5$, the doublet at $4.92 \mathrm{ppm}$ to proton $\mathrm{B}$ and the doublet at 4.24 to proton $\mathrm{C}$. Interaction of proton $\mathrm{H}-5$ with proton $\mathrm{B}$ is also visible in $\mathrm{HMBC}$ spectrum. The signal at $6.53 \mathrm{ppm}$ was assigned to proton A based on COSY interaction with proton $\mathrm{C}$. The rather large high-field shift of the aromatic proton $\mathrm{H}-5$ can be explained by an anisotropic effect of the tolyl group and thus confirms the cis orientation of protons B and C.
The structure of the minor photoproduct 12, different from the structure 11 only in trans orientation of the protons B and C, was also evident from NMR spectra by using 2D NMR techniques. The doublets at $4.90 \mathrm{ppm}$ and $4.37 \mathrm{ppm}$ with a coupling constant of $15.6 \mathrm{~Hz}$ are assigned to geminal protons $\mathrm{G}$. The singlet at $6.57 \mathrm{ppm}$ is assigned to proton A. The chemical shift of proton A is the same as in structure 11. The other two signals at $3.97 \mathrm{ppm}$ and $4.70 \mathrm{ppm}$ appear as singlets, and they are assigned to protons $\mathrm{C}$ and $\mathrm{B}$, respectively, based on weak interactions in the COSY and NOESY spectra. Nevertheless, the proton $\mathrm{H}-5$ of the fused benzene ring in structure $\mathbf{1 2}$ is in the multiplet together with other aromatic protons, which is in accordance with the proposed structure.

The structure of the photoproducts was confirmed by an additional experiment on the crude reaction mixture with DDQ (Scheme 4) in which, as expected for the predicted structures, the aromatization reaction took place forming the pyrazoloisoindole 13. Compound $\mathbf{1 3}$ arose also on silica gel during the purification of either $\mathbf{1 1}$ or $\mathbf{1 2 .}$

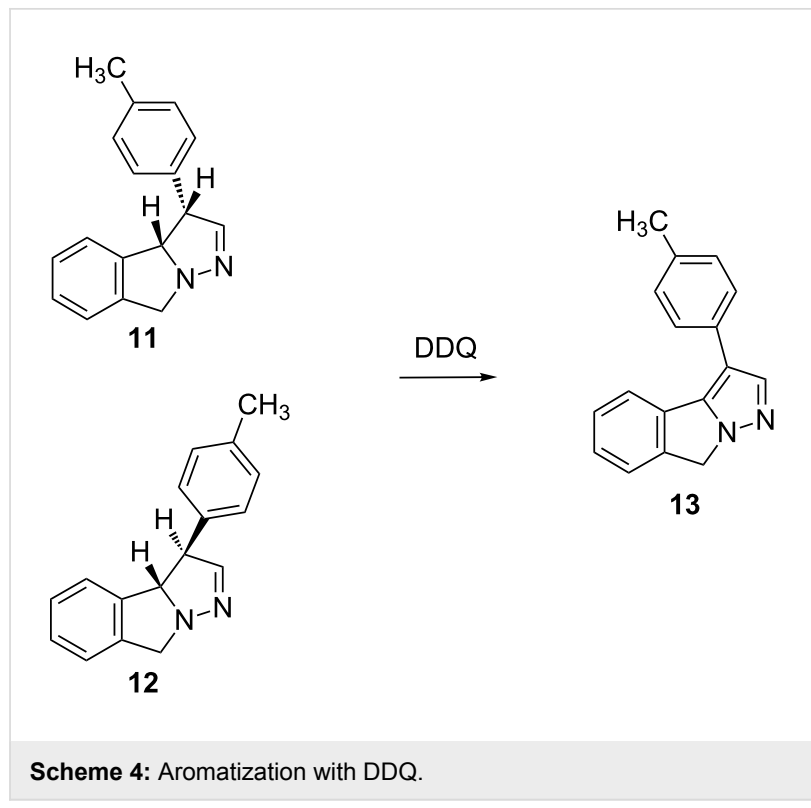<smiles>Cc1ccc(C=Cc2ccccc2C[N+]23CO[C@H](ON2)O3)cc1</smiles>

3a,b
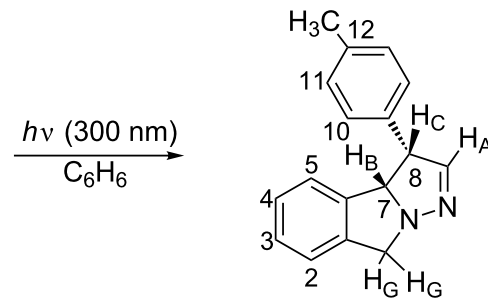

11

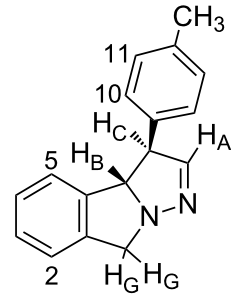

12 
The irradiation of $\mathbf{3 a}$ or $\mathbf{3 b}$ until full conversion, as previously mentioned, produced a mixture of $\mathbf{1 1}$ and $\mathbf{1 2}$ along with decomposition and high-molecular-weight products. On shorter irradiation time (10 $\mathrm{min}$, in benzene or acetonitrile) 3a (trans isomer) afforded, according to ${ }^{1} \mathrm{H} \mathrm{NMR}$, the photomixture of predominantly $\mathbf{3 b}$ (cis isomer) with only traces of starting $\mathbf{3 a}$ and tricyclic photoproducts $\mathbf{1 1}$ and $\mathbf{1 2}$. Under the same irradiation conditions, $\mathbf{3 b}$ (cis isomer) as starting compound gave a photomixture of $c i s$ isomer and the newly formed product $\mathbf{1 1}$ in 1:1 ratio with only traces of $\mathbf{3 a}$ (trans isomer), along with some unidentified side products. The experimental results show that the trans-(3a) and cis-(3b) isomerize and react with different efficiency, and that the isomerization, as in the case of stilbene itself [27], is shifted toward the cis isomer. It follows that the reaction is stereospecific and that photoproduct $\mathbf{1 1}$ is formed from the cis configuration of the stilbene moiety and the photoproduct 12 from the trans configuration, although the formation of $\mathbf{1 2}$ via epimerization of $\mathbf{1 1}$ could not be eliminated. It is also evident that there are several competitive processes, which are summarized in Scheme 5.

On irradiation of $\mathbf{3 a}$ (trans) or $\mathbf{3 b}$ (cis) parallel competitive processes are in operation, namely, trans-cis and cis-trans isomerization of the stilbene moiety, and photolysis of the sydnone ring resulting in the formation of the nitrile imine intermediate. The nitrile imine species is, in intramolecular dipolar $[3+2]$ cycloaddition, trapped by the cis- or trans-double bond of the stilbene, giving cycloadducts $\mathbf{1 1}$ or $\mathbf{1 2}$, respectively.

We also performed the thermal intramolecular reactions with the starting compounds $\mathbf{3 a}$ and $\mathbf{3 b}$. Theoretically the intramolecular 1,3-dipolar cycloaddition of the sydnone moiety, acting

as a masked azomethine dipole, and the double bond of the stilbene moiety could proceed in different ways. The orientation of the sydnone ring toward the $\pi$ bond of the stilbene in combination with the double bond configuration can give various formal $[3+2]$ intramolecular cycloadducts.

On heating of 3a (trans) in toluene until full conversion $(4 \mathrm{~h})$ one product in $50 \%$ yield was isolated from the reaction mixture after column chromatography. From the molecular ion ( $m / z$ 248) of the product and its ${ }^{13} \mathrm{C}$ NMR spectrum it was obvious that in the cycloaddition $\mathrm{CO}_{2}$ elimination took place. Fragmentation of the product and the presence of an ion at $\mathrm{m} / \mathrm{z}$ 220 suggests a structure in which the expulsion of nitrogen is possible. The structure 14 (Scheme 6) was determined by additional NMR techniques, NOE and HMBC interactions, and by single crystal X-ray structure analysis (Figure 4) of the crystal formed in an NMR tube by slow evaporation of the solvent.<smiles></smiles>

$3 \mathbf{a}$

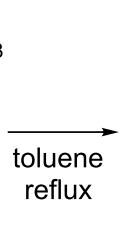

reluene
reflux$$
\text { of trans-3. }
$$

Scheme 6: Thermal reaction of trans-3.

Also, when compound $\mathbf{3 b}(\mathrm{cis})$ was refluxed in xylene $(9 \mathrm{~h})$ or toluene $(19 \mathrm{~h})$ only one cycloadduct 15 was isolated (Scheme 7), besides decomposition products, in $22 \%$ yield. The structure of $\mathbf{1 5}$ was determined by spectroscopic methods.<smiles></smiles>

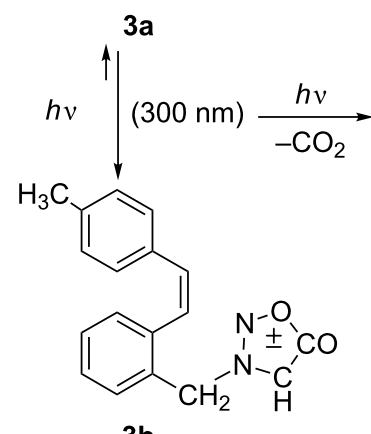<smiles>Cc1ccc(/C=C/c2ccccc2CN2C=N2)cc1</smiles><smiles>[C-]#[N+]NCc1ccccc1/C=C/N(Cc1ccccc1/C=C/c1ccc(C)cc1)[N+]#C</smiles>

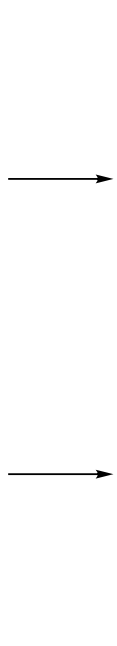

12<smiles>Cc1ccc([C@H]2C=NN3Cc4ccccc4[C@H]23)cc1</smiles>

11 


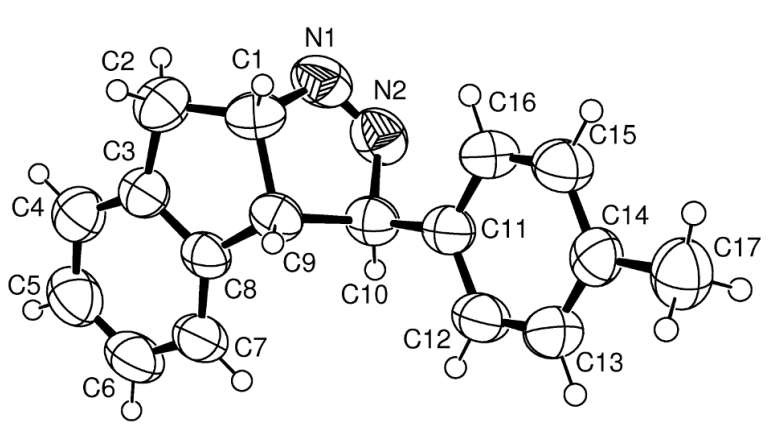

Figure 4: ORTEP of compound 14.

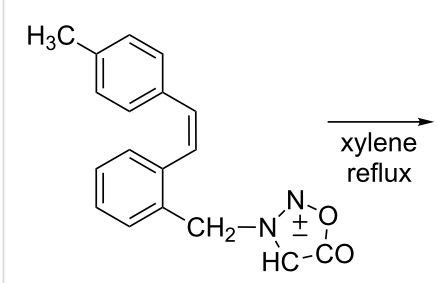

$3 \mathbf{b}$

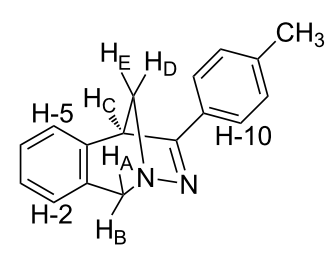

15
Scheme 7: Thermal reaction of cis-3.

In the ${ }^{1} \mathrm{H}$ NMR spectrum two pairs of geminal protons were found at 4.51 and $4.21 \mathrm{ppm}$ (A, B) and at 3.71 and $3.35 \mathrm{ppm}$ (E, D). The doublet at $3.95 \mathrm{ppm}$, coupled with one geminal proton (D), was assigned to proton $\mathrm{C}$. In the ${ }^{13} \mathrm{C}$ NMR spectrum, one of the five quaternary carbons is shifted to $176 \mathrm{ppm}$, which corresponds to an $\mathrm{sp}^{2}$-carbon in the vicinity of nitrogen. In the NOESY spectrum the interaction of protons A and B with an aromatic proton (H-2) at $7.00 \mathrm{ppm}$ is seen, as well as the interaction of proton $\mathrm{C}$ with protons $\mathrm{E}$ and $\mathrm{D}$. Since the NOE interaction is seen between protons $\mathrm{A}$ and $\mathrm{E}$ we concluded that protons $\mathrm{A}$ and $\mathrm{E}$ must lie on the same side of the six-membered ring. In addition, the interaction of proton $\mathrm{C}$ with tolyl (H-10) and $\mathrm{H}-5$ protons was seen.

In order to explain the diverse structures (14 and 15) and their formation mechanism, we analysed the possible ways of intramolecular $[3+2]$ cycloaddition relating to the arrangement of the sydnone ring towards the cis and trans double bond (Figure 5 and Figure 6).

As presented in Figure 5, the sydnone ring could be oriented to the double bond in such a way that the bonds are formed at the $\mathrm{C}(\mathrm{Sy})-\alpha(\mathrm{St})$ and $\mathrm{N}(\mathrm{Sy})-\beta(\mathrm{St})$ positions, or, as presented in Figure 6 , at the $\mathrm{N}(\mathrm{Sy})-\alpha(\mathrm{St})$ and $\mathrm{C}(\mathrm{Sy})-\beta(\mathrm{St})$ positions. The favoured arrangement of the sydnone ring toward the cis and<smiles></smiles>

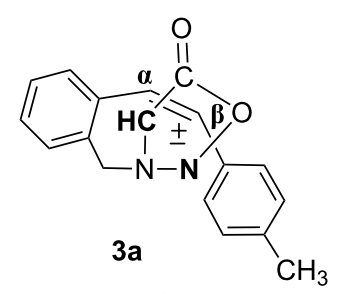

$\mathbf{C}-\mathbf{N}(\mathbf{S y})$ and $\boldsymbol{\alpha}-\boldsymbol{\beta}(\mathbf{S t})$ arrangement

Figure 5: Proposed stereochemical pathway of sydnone ring $(\mathbf{C H}-\mathrm{N})$ and trans- and cis-stilbene $(\boldsymbol{\alpha}-\boldsymbol{\beta})$.

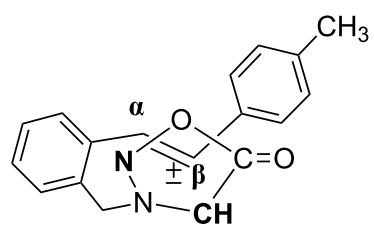

$3 \mathbf{b}$

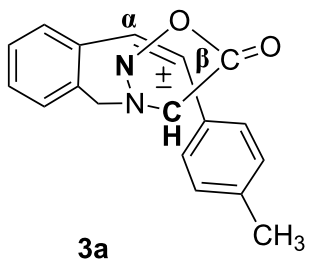

$3 a$
Figure 6: Proposed stereochemical pathway of sydnone ring $(\mathrm{N}-\mathrm{CH})$ and trans- and cis-stilbene $(\boldsymbol{\alpha}-\boldsymbol{\beta})$.

trans double bond, leading to the products, is the pathway presented in Figure 5. The regiospecific and stereospecific formation of the products $\mathbf{1 4}$ and $\mathbf{1 5}$ could be explained by this approach of the sydnone ring (Scheme 8). The cycloadducts, $\mathbf{c A}$ from trans isomer and $\mathbf{c B}$ from cis isomer, lose $\mathrm{CO}_{2}$ under the reaction conditions to afford intermediates $14 \mathrm{~A}$ and $14 \mathrm{~B}$, respectively. Owing to the favourable conformation in the case of biradical $15 \mathrm{~A}$, the $1,3-\mathrm{H}$ abstraction and formation of the $\mathrm{C}-\mathrm{N}$ double bond in product 15 is possible. In the biradical 14A the intramolecular hydrogen abstraction is not favourable, but 1,2alkyl shift takes place followed by formation of the $\mathrm{N}-\mathrm{N}$ double bond in product 14 .

Monitoring the reaction by thin layer chromatography revealed that the $[3+2]$ cycloaddition is much faster in the case of the trans isomer (3a). After the $4 \mathrm{~h}$ reflux of the toluene solution of the trans isomer, the ${ }^{1} \mathrm{H}$ NMR spectrum of the crude reaction mixture showed complete conversion, while the cis isomer (3b) under the same conditions showed complete conversion only after $19 \mathrm{~h}$. This evidence led us to believe that the formation of the $" \mathrm{C}-\alpha / \mathrm{N}-\beta$ " adduct $\mathbf{c A}$ proceeds via an energetically favoured transition state due to a possible secondary $\pi-\pi$ interaction of the tolyl and carbonyl groups. 


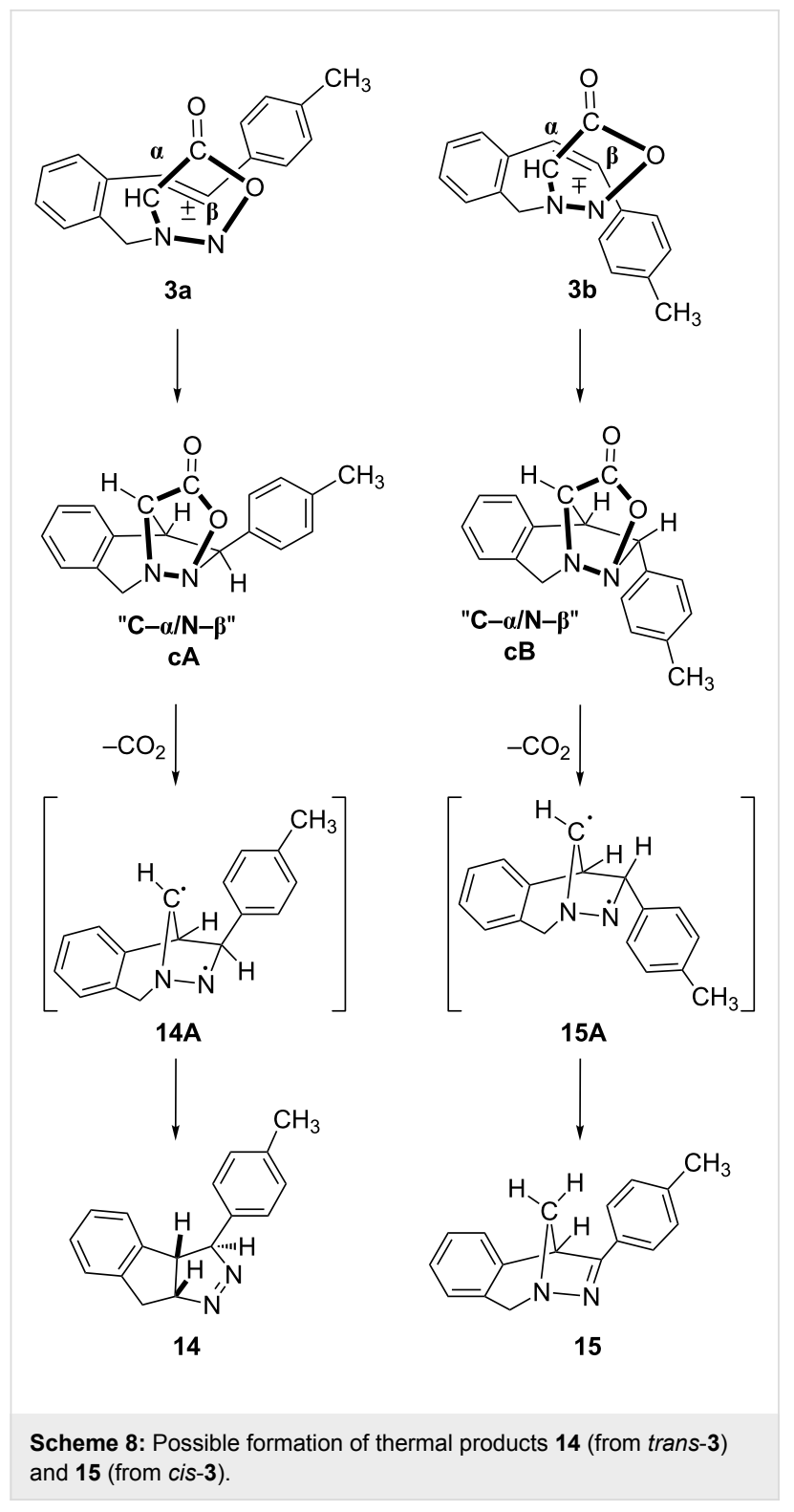

\section{Conclusion}

In photochemical and thermal intramolecular reactions the investigated compounds $\mathbf{3 a}$ and $\mathbf{3} \mathbf{b}$, in which the stilbene and sydnone ring are bridged by a methylene group, show the characteristic reaction for stilbene and sydnone moieties. The stilbene moiety photochemically isomerizes and the process of trans-cis isomerization is in competition with the photolysis of the sydnone ring. Photolysis of the sydnone moiety leads to a nitrile imine, followed by its intramolecular trapping by the $c i s$ or trans double bond of stilbene moiety, affording polycyclic compounds 11 and 12, respectively. The same starting compounds also react thermally: The sydnone moiety in $\mathbf{3 a}$ reacts as a masked azomethine dipole with trans configuration on the stilbene moiety by intramolecular [3+2] cycloaddition, giving polycyclic compound $\mathbf{1 4}$, while the sydnone moiety in the cis isomer $\mathbf{3 b}$ gives polycyclic compound $\mathbf{1 5}$. Stilbene-methylenesydnones are useful substrates for photochemical and thermal intramolecular $[3+2]$ cycloaddition reactions to heteropolycyclic compounds.

\section{Supporting Information}

\section{Supporting Information File 1}

Experimental details and characterization data for all compounds.

[http://www.beilstein-journals.org/bjoc/content/ supplementary/1860-5397-7-196-S1.pdf]

\section{Supporting Information File 2}

${ }^{1} \mathrm{H}$ NMR and APT spectra of 3a, 3b, 11-15, NOESY spectra of 11, 12, 14 and 15 and X-ray data for 14. [http://www.beilstein-journals.org/bjoc/content/ supplementary/1860-5397-7-196-S2.pdf]

\section{Acknowledgements}

This work was supported by grants from the Ministry of Science, Education and Sports of the Republic of Croatia (grant nos. 125-0982933-2926, 098-0982929-2917, 098-11913442943).

\section{References}

1. Stewart, F. H. C. Chem. Rev. 1964, 64, 129-147. doi:10.1021/cr60228a004

2. Newton, C. G.; Ramsden, C. A. Tetrahedron 1982, 38, 2965-3011. doi:10.1016/0040-4020(82)80186-5

3. Clapp, L. B. 1,2,3- and 1,2,4-Oxadiazoles. In Comprehensive Heterocyclic Chemistry; Katritzky, A. R.; Rees, C. W., Eds.; Pergamon Press: Oxford, 1984; Vol. 6, pp 365-378. doi:10.1016/B978-008096519-2.00089-8

4. Gribble, G. W. Mesoionic Ring Systems. In Synthetic Applications of 1,3-Dipolar Cycloaddition Chemistry Toward Heterocycles and Natural Products; Padwa, A.; Pearson, W. H., Eds.; Wiley \& Sons: New Jersey, 2003; pp 681-753.

5. Browne, D. L.; Harrity, J. P. A. Tetrahedron 2010, 66, 553-568. doi:10.1016/j.tet.2009.10.085

6. Chang, E.-M.; Chen, T.-H.; Wong, F. F.; Chang, E.-C.; Yeh, M.-Y. Synlett 2006, 901-904. doi:10.1055/s-2006-939041

7. Rai, G.; Puranik, V. G.; Kalluraya, B.; Hedge, J. C. Synth. Commun. 2006, 36, 1285-1290. doi:10.1080/00397910500518874

8. Krauch, C. H.; Kuhls, J.; Piek, H.-J. Tetrahedron Lett. 1966, 7, 4043-4048. doi:10.1016/S0040-4039(00)90284-3

9. Chinone, A.; Huseya, Y.; Ohta, M. Bull. Chem. Soc. Jpn. 1970, 43, 2650. doi:10.1246/bcsj.43.2650

10. Huseya, Y.; Chinone, A.; Ohta, M. Bull. Chem. Soc. Jpn. 1971, 44, 1667-1668. doi:10.1246/bcsj.44.1667

11. Märky, M.; Hansen, H.-J.; Schmid, H. Helv. Chim. Acta 1971, 54, 1275-1278. doi:10.1002/hlca.19710540506

12. Gotthardt, H.; Reiter, F. Tetrahedron Lett. 1971, 12, 2749-2752. doi:10.1016/S0040-4039(01)96970-9 
13. George, M. V.; Angadiyavar, C. S. J. Org. Chem. 1971, 36, 1589-1594. doi:10.1021/jo00811a004

14. Gotthardt, H.; Reiter, F. Chem. Ber. 1979, 112, 1206-1225. doi:10.1002/cber.19791120415

15. Gotthardt, H.; Reiter, F. Chem. Ber. 1979, 112, 1635-1649. doi:10.1002/cber.19791120514

16. Pfoertner, K.-H.; Foricher, J. Helv. Chim. Acta 1980, 63, 653-657. doi:10.1002/hlca.19800630312

17. Butković, K.; Basarić, N.; Lovreković, K.; Marinić, Ž.; Višnjevac, A.; Kojić-Prodić, B.; Šindler-Kulyk, M. Tetrahedron Lett. 2004, 45, 9057-9060. doi:10.1016/j.tetlet.2004.10.036

18. Meier, H.; Heimgartner, H.; Schmid, H. Helv. Chim. Acta 1977, 60, 1087-1090. doi:10.1002/hlca.19770600333

19. Meier, H.; Heimgartner, H. Helv. Chim. Acta 1986, 69, 927-940. doi:10.1002/hlca.19860690421

20. Yeu, J.-P.; Yeh, J.-T.; Chen, T.-Y.; Uang, B.-J. Synthesis 2001 1775-1777. doi:10.1055/s-2001-17517

21. Butković, K.; Marinić, Ž.; Šindler-Kulyk, M. Magn. Reson. Chem. 2004, 42, 1053-1055. doi:10.1002/mrc.1488

22. Butković, K.; Vuk, D.; Marinić, Ž.; Penić, J.; Šindler-Kulyk, M. Tetrahedron 2010, 66, 9356-9362. doi:10.1016/j.tet.2010.10.013

23. Butković, K.; Marinić, Ž.; Šindler-Kulyk, M. ARKIVOC 2011, 10, 1-15.

24. Gorsane, M.; Defay, N.; Martin, R. H. Bull. Soc. Chim. Belg. 1985, 94 , 215-231. doi:10.1002/bscb.19850940309

25. Palmer, B. D.; Thompson, A. M.; Booth, R. J.; Dobrusin, E. M.; Kraker, A. J.; Lee, H. H.; Lunney, E. A.; Mitchell, L. H.; Ortwine, D. F.; Smaill, J. B.; Swan, L. M.; Denny, W. A. J. Med. Chem. 2006, 49, 4896-4911. doi:10.1021/jm0512591

26. Husemoen, G.; Olsson, R.; Andersson, C.-M.; Harvey, S. C.; Hansen, H. C. J. Comb. Chem. 2003, 5, 606-609. (The isomers are not separarted.)

27. Saltiel, J.; Sears, D. F., Jr.; Ko, D.-H.; Park, K.-M. Cis-Trans Isomerization of Alkenes. In CRC Handbook of Photochemistry and Photobiology; Horspool, W., Ed.; CRC Press: Boca Raton, 1995; pp 3-15.

\section{License and Terms}

This is an Open Access article under the terms of the Creative Commons Attribution License (http://creativecommons.org/licenses/by/2.0), which permits unrestricted use, distribution, and reproduction in any medium, provided the original work is properly cited.

The license is subject to the Beilstein Journal of Organic Chemistry terms and conditions:

(http://www.beilstein-journals.org/bjoc)

The definitive version of this article is the electronic one which can be found at: $\underline{\text { doi: } 10.3762 / \text { bjoc. } 7.196}$ 